\title{
Evolution and Trend of the Outgoing Longwave Radiation Spectrum
}

\author{
YI HUANG* \\ Princeton University, Princeton, New Jersey \\ V. RAMASWAMY \\ NOAA/Geophysical Fluid Dynamics Laboratory, Princeton, New Jersey
}

(Manuscript received 3 October 2008, in final form 23 April 2009)

\begin{abstract}
The variability and change occurring in the outgoing longwave radiation (OLR) spectrum are investigated by using simulations performed with a Geophysical Fluid Dynamics Laboratory coupled atmosphere-oceanland general circulation model. First, the variability in unforced climate (natural variability) is simulated. Then, the change of OLR spectrum due to forced changes in climate is analyzed for a continuous 25-yr time series and for the difference between two time periods (1860s and 2000s). Spectrally resolved radiances have more pronounced and complex changes than broadband fluxes. In some spectral regions, the radiance change is dominated by just one controlling factor (e.g., the window region and $\mathrm{CO}_{2}$ band center radiances are controlled by surface and stratospheric temperatures, respectively) and well exceeds the natural variability. In some other spectral bands, the radiance change is influenced by multiple and often competing factors (e.g., the water vapor band radiance is influenced by both water vapor concentration and temperature) and, although still detectable against natural variability at certain frequencies, demands stringent requirements (drift less than $0.1 \mathrm{~K} \mathrm{decade}^{-1}$ at spectral resolution no less than $1 \mathrm{~cm}^{-1}$ ) of observational platforms. The difference between clear-sky and all-sky radiances in the forced climate problem offers a measure of the change in the cloud radiative effect, but with a substantive dependence on the temperature lapse rate change. These results demonstrate that accurate and continuous observations of the OLR spectrum provide an advantageous means for monitoring the changes in the climate system and a stringent means for validating climate models.
\end{abstract}

\section{Introduction}

High-spectral-resolution earth thermal emission spectra, particularly those measured by satellite instrumentsfor example, the Tropospheric Emission Spectroscopy (TES) onboard Aura (Beer 2006), the Atmospheric Infrared Sounder (AIRS) onboard Aqua (Chahine et al. 2006), and the Infrared Atmospheric Sounding Interferometer (IASI) onboard Met Op (Blumstein et al. 2004) have proven to be unique and advantageous for sounding atmospheric compositions and meteorological fields. In addition to the retrieval products derived from them, the spectrally resolved radiances themselves are beneficial

* Current affiliation: School of Engineering and Applied Sciences, Harvard University, Cambridge, Massachusetts.

Corresponding author address: Yi Huang, 12 Oxford St., Link 284, Cambridge, MA 02138.

E-mail: yi.huang@noaa.gov in improving weather forecast via data assimilation (e.g., Le Marshall et al. 2006) and are essential for understanding longwave climate feedbacks and examining climate models (Haskins et al. 1997; Goody et al. 1998; Huang and Yung 2005; Huang et al. 2007a; Huang and Ramaswamy 2008).

Another promising use of the thermal spectrum is its application in benchmark climate monitoring. Because the measurement of spectrally resolved radiances can be accurately calibrated to international standards in space (Goody and Haskins 1998; Anderson et al. 2004), and because it possesses high information content and global coverage, outgoing longwave radiation (OLR) spectrum observation makes an excellent candidate for a benchmark climate record. It has been understood that climate forcings can be detected and distinguished from their spectral signatures. Kiehl (1983), Charlock (1984), and Slingo and Webb (1997) compute, through numerical models, the change in the OLR spectrum in response to the increase in well-mixed greenhouse gases. 
Harries et al. (2001) show observational evidence of such spectral signatures by differencing the spectra observed by two satellite instruments flown in 1970-71 and 1997, respectively. Leroy et al. (2008) test an "optimal fingerprinting" technique that identifies the climate change signals associated with $\mathrm{CO}_{2}$ radiative forcing as well as feedbacks in the clear-sky OLR spectrum. Because of these potential opportunities in the longwave, as well as advantages in other frequencies [e.g., see the discussion of Loeb et al. (2007) for shortwave and of Ringer and Healy (2008) for radio occultation], the Climate Absolute Radiance and Refractivity Observatory (CLARREO) is recommended by the U.S. National Research Council (NRC) decadal survey (NRC 2007) with priority for the National Oceanic and Atmospheric Administration's (NOAA's) and the National Aeronautics and Space Administration's (NASA's) mission development.

The aforementioned works (i.e., Kiehl 1983; Charlock 1984; Slingo and Webb 1997; Harries et al. 2001; Leroy et al. 2008) explored the problem of monitoring climate change by using the OLR spectrum. However, these previous works limit their discussions to the clear-sky condition; furthermore, they have the limitation of using monthly-mean profiles in simulating mean radiation fields (Fig. 1). The nonlinear radiative transfer effects involving clouds prohibit the use of mean profiles to compute mean radiances. Clouds may also obscure the spectral "fingerprints" in signal detection because of their less selective absorption with respect to frequency. Huang et al. (2007a) show that all-sky spectra simulated from instantaneous model profiles are in good agreement with the AIRS observations in terms of global and regional annual means after ensuring proper sampling and cloud overlap treatment. Based on this result, we perform a modeling investigation of climate change signatures in both clear-sky and all-sky OLR spectra. Additionally, we take advantage of the over five years of AIRS (operational since August 2002) measurements to understand the OLR spectrum variation from the observational perspective and to compare with modeling results.

The climate change detection in our context is essentially a comparison between unforced variability and anthropogenic (forced) trend signals. In the following, after a description of the model configuration and satellite data processing, we first examine the "natural" variability of the OLR spectrum. Simulated radiance variabilities from the unforced model integration are examined against the AIRS observation. Then, the OLR spectrum evolution over a $25-\mathrm{yr}$ period is simulated from "forced" model integrations. We analyze how the radiances in different spectral bands vary with regards to their different controlling geophysical variables (tem- perature, water vapor, clouds, etc.) and examine whether there is a detectable trend against the unforced natural variability. We conclude with a discussion on the application of the resolved OLR spectrum to climate monitoring and model verification.

\section{Model and observation data}

\section{a. Model}

The Geophysical Fluid Dynamics Laboratory (GFDL) coupled atmosphere-ocean-land GCM (version CM2.1, hereafter CM2) (Delworth et al. 2006; Knutson et al. 2006) is employed in our numerical experiments. We take advantage of Ramaswamy et al. (2006) and Schwarzkopf and Ramaswamy (2008)'s integrations from 1861 to 2004 (extended) driven by prescribed radiative forcing agents. Following the nomenclature of Schwarzkopf and Ramaswamy (2008), "Nat" denotes the integration with natural forcing agents (solar insolation and volcanic aerosols) only; "Allforc" is the integration with all documented forcing agents $\left(\mathrm{CO}_{2}, \mathrm{CH}_{4}, \mathrm{~N}_{2} \mathrm{O}, \mathrm{CFCs}, \mathrm{O}_{3}\right.$, and anthropogenic and natural aerosols; Solomon et al. 2007); "CO2" is the integration with $\mathrm{CO}_{2}$ forcing only; "WmGhgO3" is $\mathrm{CO}_{2}$ plus other well-mixed greenhouse gases $\left(\mathrm{CH}_{4}, \mathrm{~N}_{2} \mathrm{O}, \mathrm{CFCs}\right)$ and $\mathrm{O}_{3}$; and "Anth" is WmGhgO3 forcings plus anthropogenic aerosols.

Synthetic spectra ranging from 100 to $2500 \mathrm{~cm}^{-1}$ with $1 \mathrm{~cm}^{-1}$ resolution are simulated offline by using a radiative transfer code, MODTRAN version 4 (Bernstein et al. 1996), assuming a nonscattering plane-parallel atmosphere (Goody and Yung 1989). The choice of this particular radiative transfer model as well as the configuration is a compromise between speed and spectral resolution. CM2 generates 24-layer profiles of temperature, water vapor, and clouds (fraction, liquid, and ice water concentrations). These 3-hourly archived profiles topped at about $35 \mathrm{~km}$ are patched with five layers of standard atmosphere (McClatchey et al. 1972) from 50 to $100 \mathrm{~km}$ and then fed into MODTRAN for radiance simulation. The cloud optical properties and the random overlapping assumption are treated consistently with the CM2 radiation scheme. The details are documented in Huang et al. (2007a).

To reduce the computational burden, as well as to ensure sampling consistency in the comparison with observation, we "fly" a virtual AIRS instrument (which is aboard Aqua, a sun-synchronous satellite crossing equator at 0130/1330 LT) in the CM2 spatiotemporal domain and select only those overpassed grid boxes for radiance simulation. Figure 1 illustrates the biases in the two methods (using monthly-mean profile and satellite tracking) compared to a faithful average of the instantaneous spectra computed from 3-hourly GCM outputs 
a). Bias in regional monthly mean, all-sky

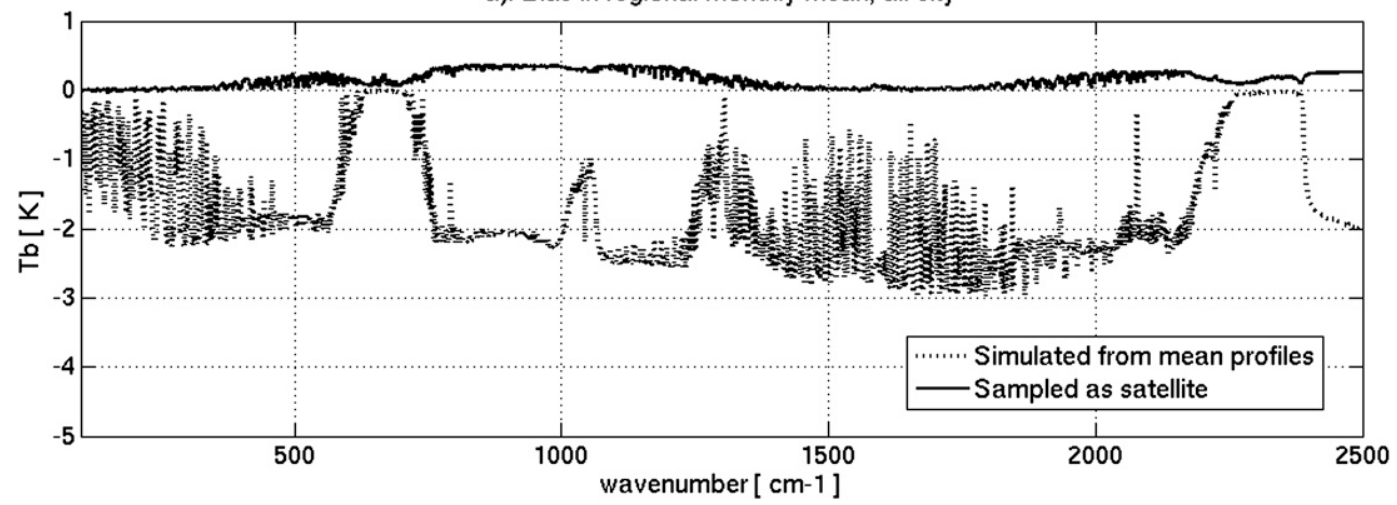

b). Bias in the difference between two regional monthly means, all-sky

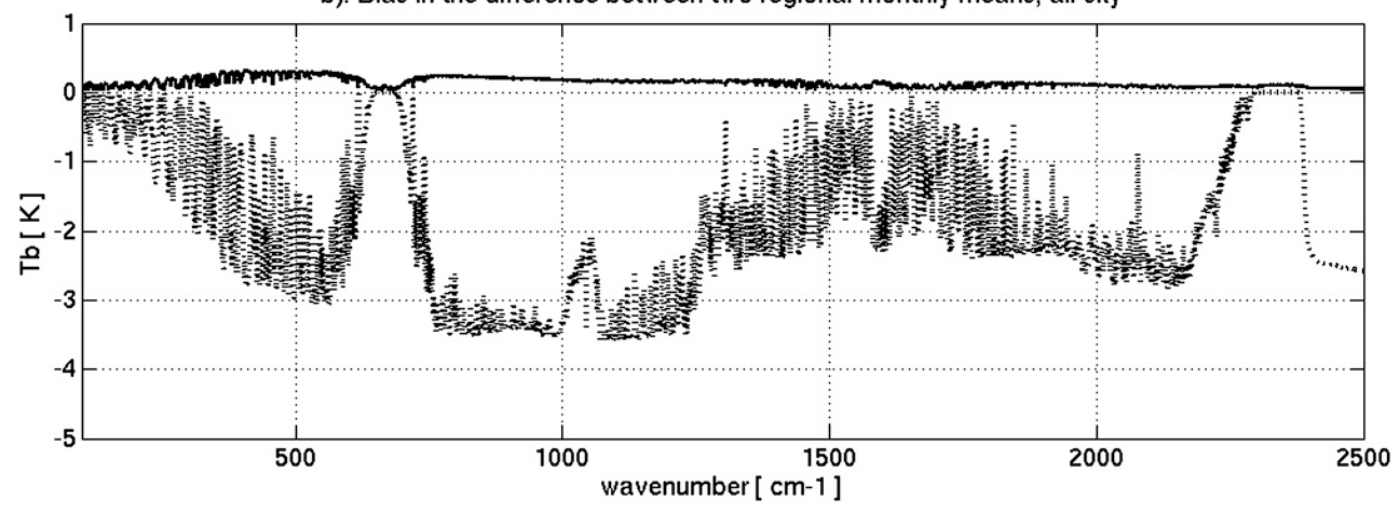

FIG. 1. Examples of spectrum bias due to using monthly mean profiles or sampling as a satellite (Aqua). (a) Bias in the regional monthly mean spectrum of the tropical $\left(30^{\circ} \mathrm{S}-30^{\circ} \mathrm{N}\right)$ ocean, January 2003 , compared to the faithful average of all instantaneous spectra simulated from CM2-generated 3-hourly profiles. (b) Bias in the difference between two regional monthly mean spectra: Equatorial $\left(10^{\circ} \mathrm{S}-10^{\circ} \mathrm{N}\right)$ oceans of $150^{\circ} \mathrm{E}-150^{\circ} \mathrm{W}$ and $150^{\circ}-90^{\circ} \mathrm{W}$. The radiances are presented as brightness temperature, $T_{b}(\mathrm{~K})$.

with respect to a regional mean, as well as the contrasts in two different regions. From Fig. 1, the satellite-tracking sampling has little impact on the mean spectrum over oceanic regions where the diurnal cycle is regular and smooth. Moreover, we simulate the spectra during the first 16 days (the repeat cycle of Aqua orbits) of each month to ensure global coverage (except for polar regions not covered by Aqua ground tracks). These procedures reduce the spectrum simulation to about $5 \%$ of all the instantaneous profiles generated by $\mathrm{CM} 2$ and essentially sample the low latitudes at two local times around noon and midnight each day.

\section{b. Satellite data}

AIRS is a grating spectrometer with 2378 channels ranging from 650 to $2665 \mathrm{~cm}^{-1}$. The instrument has a nadir footprint of $13.5 \mathrm{~km}$; the radiance measurement has a precision of $0.5 \mathrm{~K}$ at $250 \mathrm{~K}$ (Chahine et al. 2006). Following Huang et al. (2007a), only the scan views within $\pm 5^{\circ}$ are used as nadir views; among its channels, only those recommended for retrieval products and not subject to static or dynamic noises are used. The spectral resolutions of AIRS channels gradually change with a resolving power of $v / \Delta v=1200$. To make meaningful comparisons, both the observed and simulated spectra are degraded to a $2 \mathrm{~cm}^{-1}$ spaced spectral grid by convolving with a triangular scanning function with a fullwidth half-maximum of $2 \mathrm{~cm}^{-1}$.

\section{Simulated unforced "natural" variability of OLR spectrum}

Here, we are interested in the extent to which naturally occurring interannual variability inhibits the detection of the climate change on a decadal scale. Because of the insufficient length of continuous observations, we use a 20-yr period (1861-80) of the Nat CM2 experiment as a surrogate to study the unforced interannual variability of OLR spectrum. During this period, there is no major volcanic activity and the solar insolation is kept at constant value (Schwarzkopf and Ramaswamy 2008) so that the simulation represents a virtually "unforced" climate 
a). Power spectrum of radiance time series, all-sky global ocean, AIRS

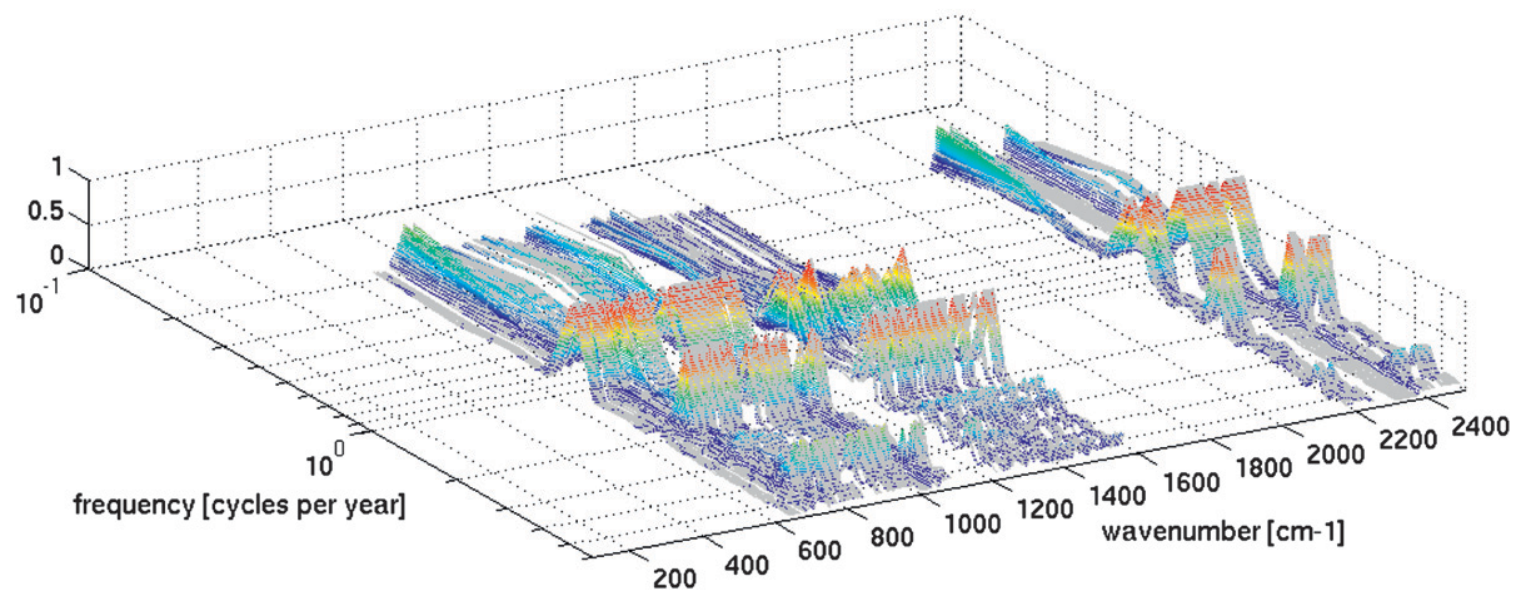

b). $\mathrm{CM} 2$

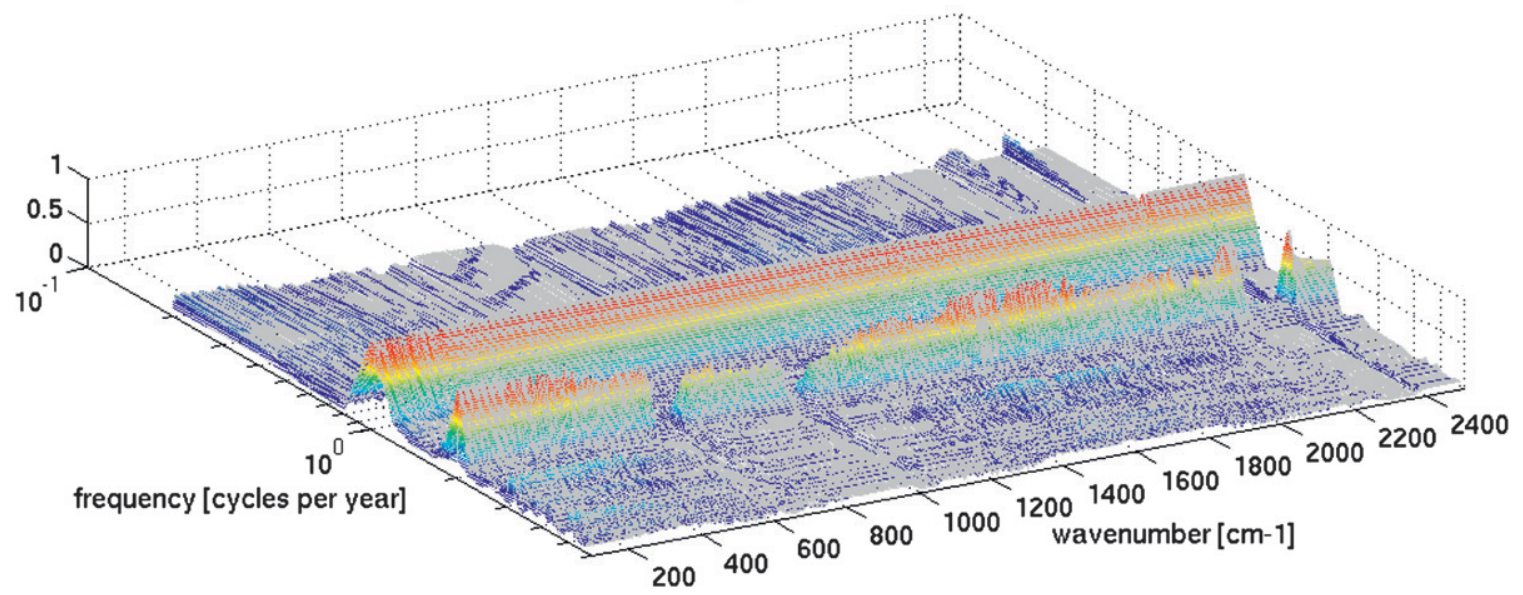

FIG. 2. Power spectrum of the all-sky global ocean mean radiance time series, plotted as a function of radiation frequency ( $x$ axis) and cyclic frequency ( $y$ axis): (a) AIRS and (b) CM2 unforced.

system, mainly consisting of the internal oscillations in the coupled atmosphere-ocean system, for which the CM2 in use is shown to have a reasonable representation (Delworth et al. 2006), particularly on the interannual scale (Wittenberg et al. 2006). Henceforth, in this study, this Nat simulation will be referred to as simulated unforced variability for convenience. Meanwhile, we use the more than five years of AIRS data as a measure of the observed spectral variability over this period.

The power spectra of the radiances at each $2 \mathrm{~cm}^{-1}$ interval are plotted in Fig. 2. For the global monthly mean time series, both observed and simulated results show remarkable annual and semiannual cycles. The observed radiances in the water vapor vibration-rotation band (1250-1600 $\mathrm{cm}^{-1}$ ) have a stronger semiannual cycle than the annual cycle whereas the simulated spectra show the opposite. AIRS spectra also show noticeable intraseasonal oscillations and a pronounced 5-yr signal (trend) at many frequencies, such as around 720 and $2250 \mathrm{~cm}^{-1}$, which is not seen in the unforced variations.

The standard deviations of the monthly- and annualmean radiances are shown in Fig. 3. The simulation captures well the monthly and interannual variabilities compared to the AIRS observation at most frequencies. The standard deviation of annual means (Fig. 3a) does not exceed $0.1 \mathrm{~K}$ throughout the spectrum in the unforced simulation, whereas the observation containing $\mathrm{CO}_{2}$ and stratospheric temperature variations shows enhanced variability in the $\mathrm{CO}_{2}$ bands. The simulation seems to have stronger interannual variability in the water vapor vibration-rotation band $\left(1250-1600 \mathrm{~cm}^{-1}\right)$. However, considering that the 5-yr (September 2002August 2007) AIRS observations used here do not contain any very strong ENSO event, it is not certain whether the interannual variability is indeed overestimated in the simulation. The monthly variability 
a). Standard deviation of annual mean radiances

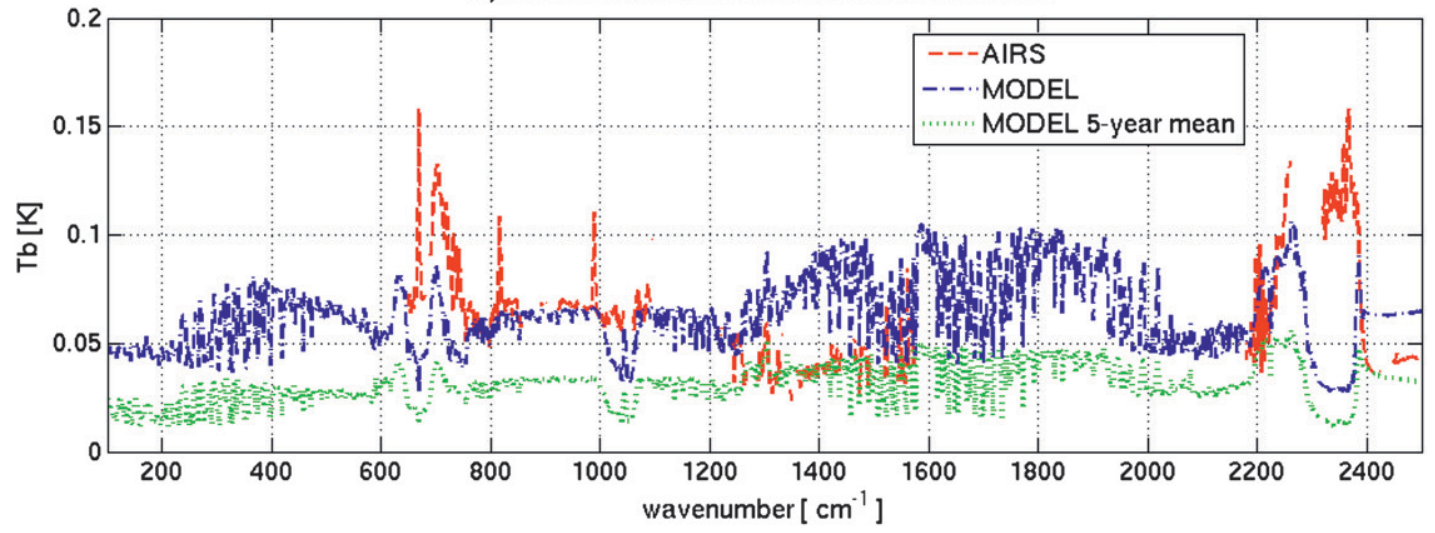

b). Standard deviation of monthly mean radiances

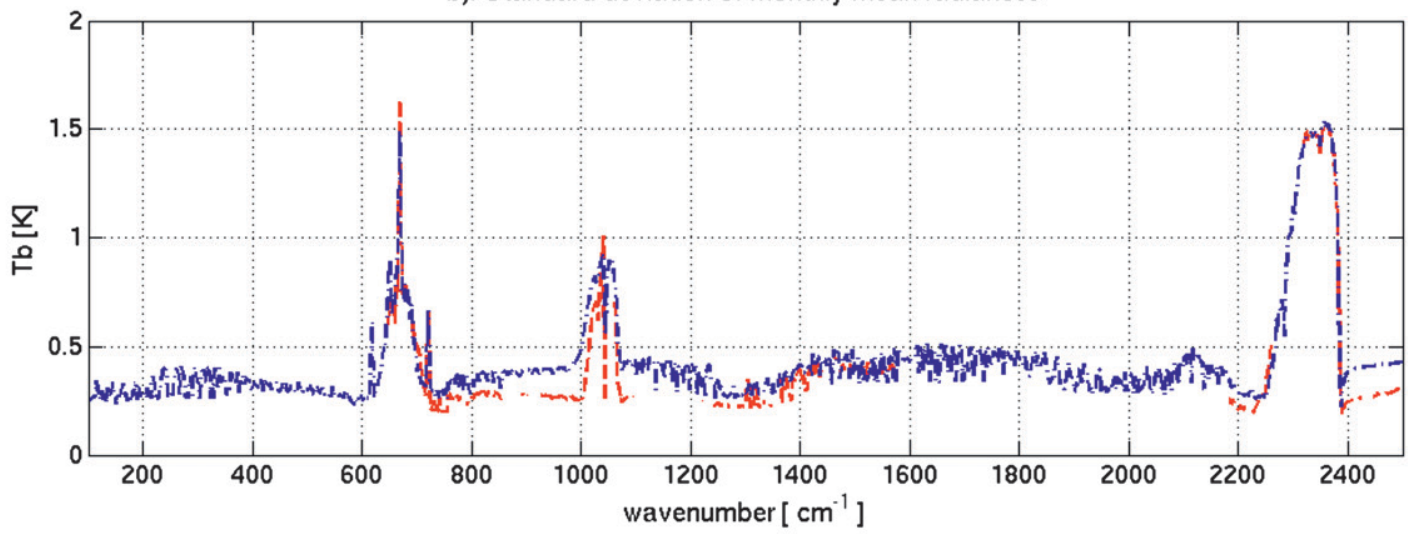

c). Decompositionn of the radiance variation

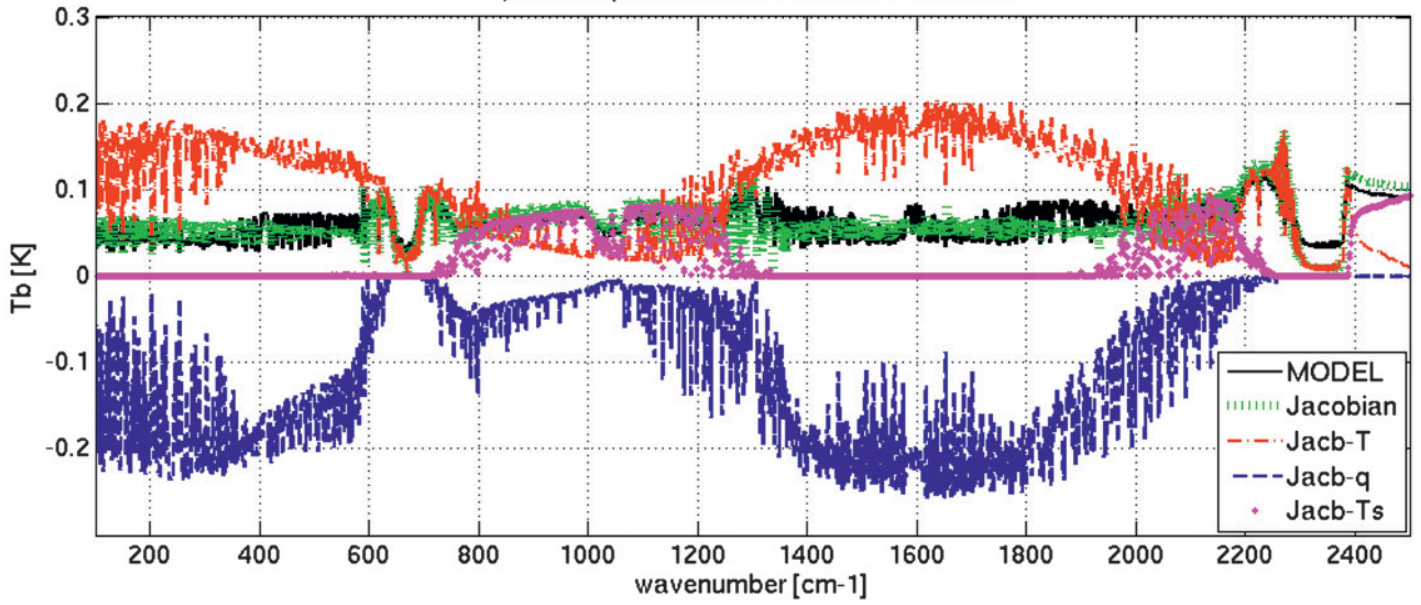

FIG. 3. Standard deviations of (a) annual mean radiances and (b) monthly mean radiances, computed from the time series of all-sky global means. "MODEL" and "AIRS" indicate the results simulated from CM2 and obtained from AIRS observation, respectively; as a comparison, also shown in (a) is the standard deviation of 5-yr mean radiances. (c) Standard variation of different components that contribute to the overall radiance variation. "MODEL" is the standard deviation of the model-simulated clear-sky global annual mean radiances; "Jacobian" represents the standard deviation of the radiance variation reproduced by using radiative Jacobians [see the text as well as Huang et al. (2007a,b)]; and Jacb-T, Jacb-q, and Jacb-Ts represent the standard deviations that would arise from atmospheric temperature, water vapor (note: plotted as the negative of the actual quantity to emphasize the compensating contributions), and surface temperature, respectively. 
a). clr-sky Global ocean annual mean radiance change

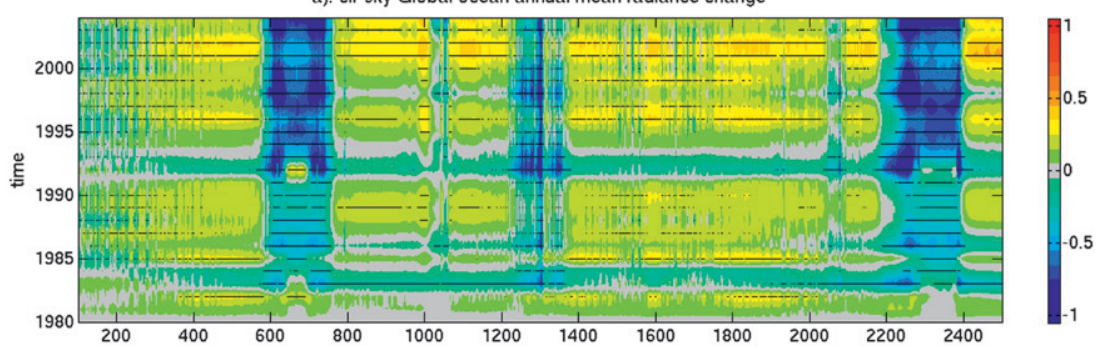

b). all-sky Global ocean annual mean radiance change

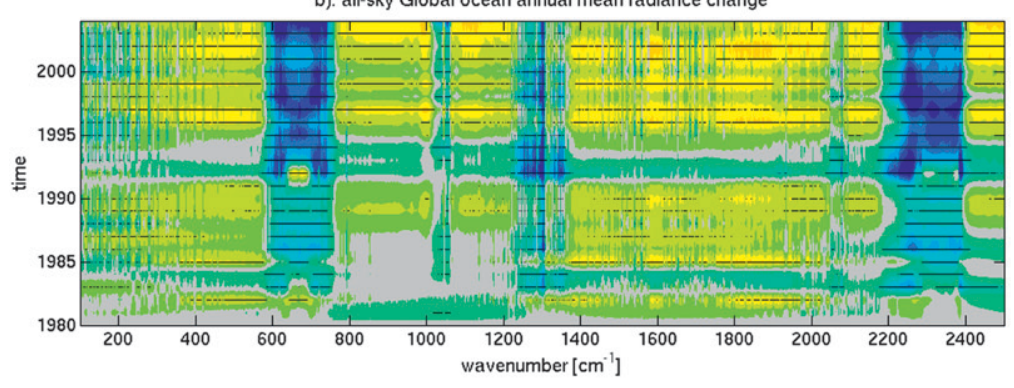

c). global ocean annual mean cloud forcing change

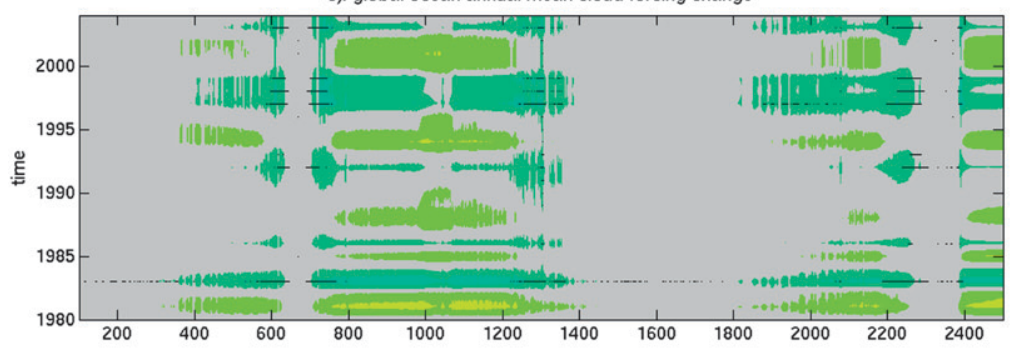

d). expanded view of a)

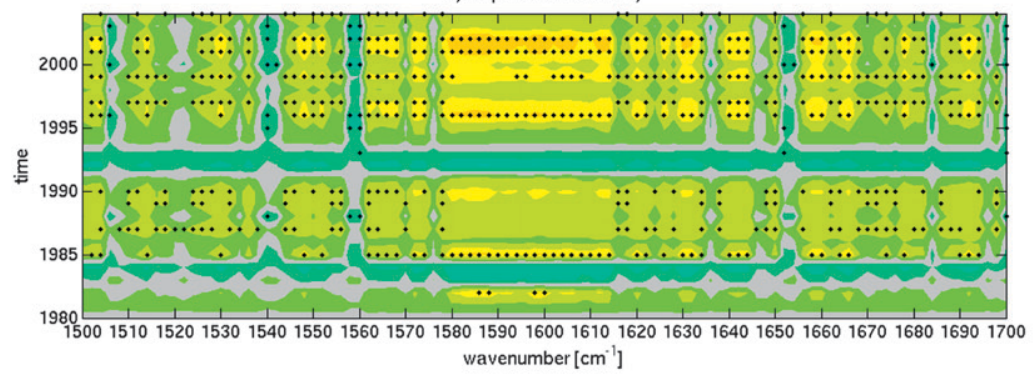

e) difference spectrum

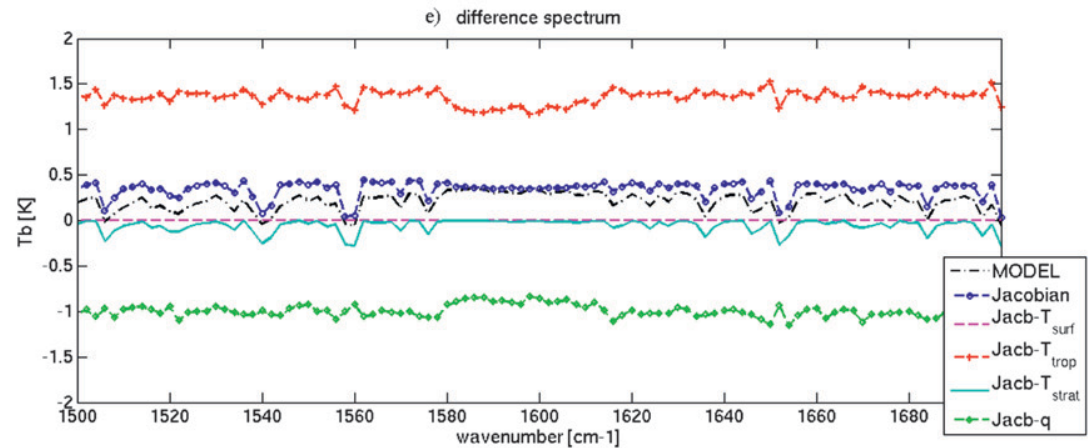


(Fig. 3b) is much stronger than the interannual variability. The magnitude of the monthly standard deviations ranges between 0.3 and $0.5 \mathrm{~K}$ at most frequencies except in the $\mathrm{CO}_{2}$ and $\mathrm{O}_{3}$ bands, where the strong stratospheric seasonal cycle in temperature yields a much larger radiance variability. In contrast, averaging over longer times (e.g., 5 yr, as in Fig. 3a) damps the OLR spectrum variability.

Huang et al. (2007a,b) show that the interannual variation of clear-sky OLR can be well reproduced from the variation of surface and atmospheric temperatures and water vapor by using radiative Jacobians (the partial derivatives of OLR with respect to these variables). As shown in Fig. 3c, in the water vapor bands (the rotational band is $100-560 \mathrm{~cm}^{-1}$; the vibration-rotation band is $1250-2000 \mathrm{~cm}^{-1}$ ), the very small radiance variability $(\sim 0.05 \mathrm{~K})$ results from compensating temperature and water vapor contributions of much larger individual magnitude. In the atmospheric windows $\left(800-1250 \mathrm{~cm}^{-1}\right.$, 2000-2200 $\mathrm{cm}^{-1}$, and $2400 \mathrm{~cm}^{-1}$ and beyond), the spectral variability is mostly due to surface temperature change. It is also noted that there is no substantial difference between the simulated clear-sky and all-sky standard deviations (not shown).

\section{Evolution of OLR spectrum (1980-2004)}

We rely on the abovementioned CM2 simulations (Schwarzkopf and Ramaswamy 2008) to investigate how the OLR spectrum evolves with time. The last $25 \mathrm{yr}$ (1980-2004) from one realization of the Allforc experiment is used for examining the continuous change in the OLR spectrum. This period includes two major volcanic eruptions (El Chichon in 1982 and Pinatubo in 1991) and also the most rapid warming to date during the industrial period (Solomon et al. 2007). Because the resolved radiances at different frequencies are sensitive to geophysical variables at different altitudes (Huang et al. 2007b), the evolution of the OLR spectrum serves as a good indicator of the undergoing atmospheric and surface changes. This period is also when observations by a variety of satellite instruments became available, so the radiative signatures of climate change can be detected in satellite observations (e.g., Soden et al. 2005) and understood with the aid of climate models.

Figure 4 illustrates the 25-yr time series of global ocean annual mean OLR spectra simulated from CM2. The accompanying evolutions of surface temperature, atmospheric temperature, water vapor concentration, cloud condensate concentration (the sum of liquid and ice waters times cloud fraction), and OLR are shown in Fig. 5. The standard deviations of these variables (temperature, specific humidity, cloud condensate and radiance) in the Nat experiment are used as a measure of unforced variability. If a change relative to the 1980 value is larger than 3 times the standard deviation in Nat, it is marked as a "significant" change. Though an arbitrary choice, this assumption enables quantification and is probably a conservative marker in terms of declaring subjective detectability. The radiance trends in each $2 \mathrm{~cm}^{-1}$ interval estimated from linear regression are shown in Fig. 6, together with their associated uncertainty intervals measured by the method of Weatherhead et al. (1998), which takes into account both random fluctuations and possible autoregression processes in the time series.

The radiance evolution and trends in the major spectral bands in the OLR spectrum are analyzed below.

From Fig. 4, the most prominent change in both clearsky and all-sky spectra is the decrease of brightnesstemperature in the $\mathrm{CO}_{2} 667$ and $2350 \mathrm{~cm}^{-1}$ bands and the $\mathrm{CH}_{4} 1310 \mathrm{~cm}^{-1}$ band. The cooling trend at the center of the abovementioned $\mathrm{CO}_{2}$ bands, which reflects the stratospheric temperature decrease (the correlation between $667 \mathrm{~cm}^{-1}$ radiance and $10-\mathrm{hPa}$ temperature is 0.99 ), is interrupted by the momentary warming caused by the aerosols from the two volcanic eruptions in 1982 and 1991 (Fig. 5d) (see Ramaswamy et al. 2006). Interestingly, the cooling on both sides of the band centers is actually stronger than that at the centers. This is because the increase of absorber $\left(\mathrm{CO}_{2}\right)$ concentration raises the effective emitting level of outgoing radiances to a higher and thus substantially colder altitude in the troposphere (true for the wings of these bands). The same reasoning

FIG. 4. Evolution of (a) clear-sky and (b) all-sky global ocean annual mean radiance changes relative to 1980 due to all forcing agents (Allforc). Changes larger than 3 times the standard deviation of unforced annual means are shown with black dots. (c) Change of cloud forcing (clear-sky radiance minus all-sky radiance). (d) Enlarged portion of (a) in the water vapor vibration-rotation band. (e) Decomposition of the tropical mean difference spectrum (MODEL) between the 1980-84 and 2000-04 means; "Jacobian" is the difference reconstructed from temperature and water vapor changes by using radiative Jacobians, which is further decomposed into contributions by surface temperature (Jacb-Tsurf), tropospheric temperature (Jacb-Ttrop), stratospheric temperature (Jacb-Tstrat), and water vapor (Jacb-q). 

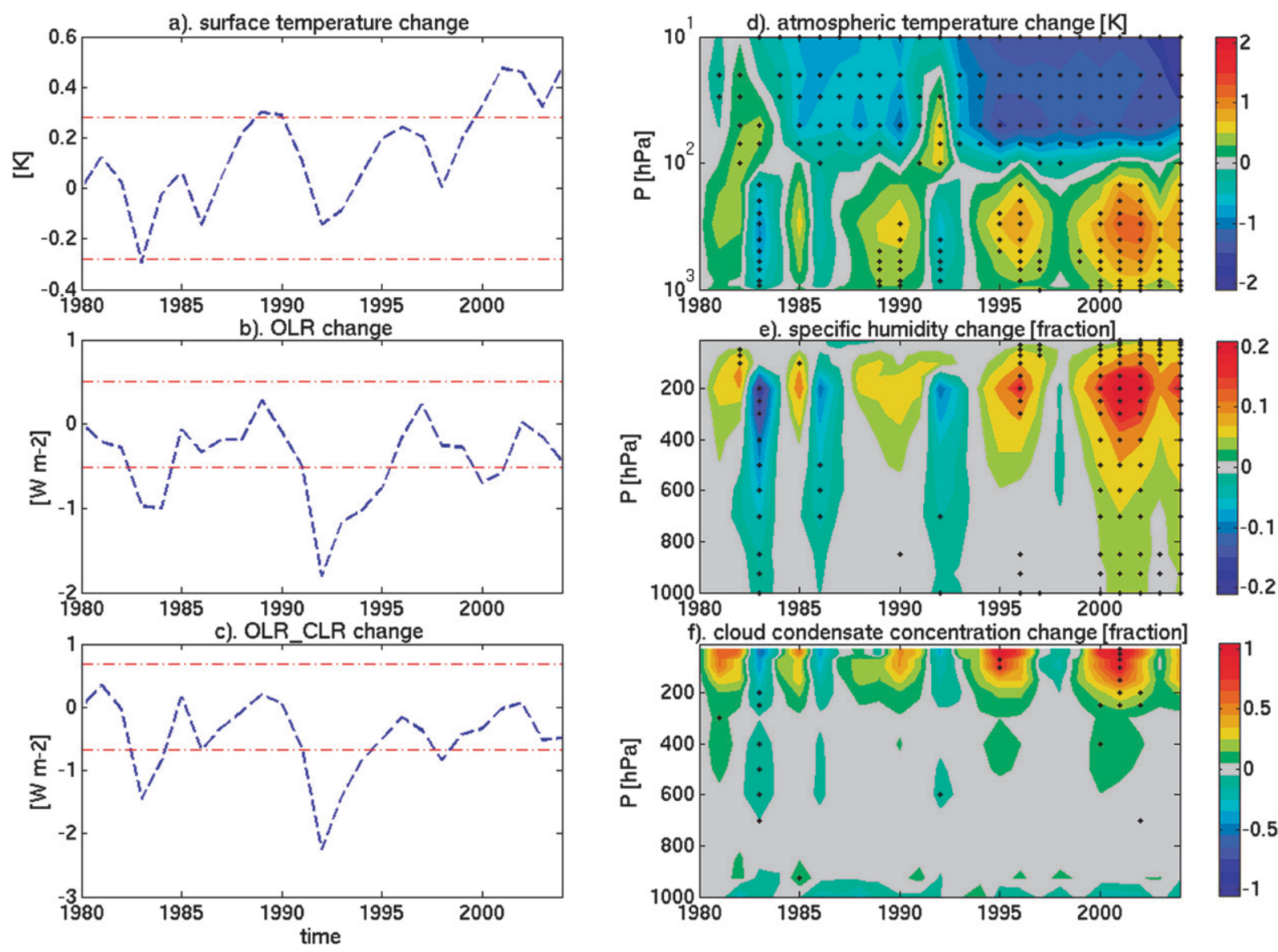

FIG. 5. Evolution of simulated (a) surface temperature, (b) all-sky OLR, (c) clear-sky OLR, (d) atmospheric temperature, (e) water vapor concentration, and (f) cloud condensate (liquid and ice water times cloud fraction) changes relative to 1980 due to all forcing agents (Allforc). Red dotted lines in (a),(b), and (c) represent 3 times the standard deviation of the unforced run. The substantial (larger than 3 times the std dev of the unforced run) changes in (d),(e), and (f) are shown with black dots. Note that (e) and (f) show mean-profilenormalized changes.

explains the pronounced cooling in the $\mathrm{CH}_{4} 1310 \mathrm{~cm}^{-1}$ band and the weaker $\mathrm{CO}_{2} 2076 \mathrm{~cm}^{-1}$ band. Despite the volcanic interruptions, the cooling trend clearly exceeds the uncertainty envelope (see Fig. 6) and thus, by the definition adopted here, is statistically significant. There is also noticeable cooling in the $\mathrm{O}_{3} 1042 \mathrm{~cm}^{-1}$ band, which also relates to stratospheric cooling. All these cooling signals (change relative to 1980) become larger than the unforced variability (3 times the interannual standard deviation in the unforced Nat run) in only a few years. This suggests that the increase of the well-mixed greenhouse gases $\left(\mathrm{CO}_{2}\right.$ and $\left.\mathrm{CH}_{4}\right)$ as well as the stratospheric temperature decreases can be detected with little ambiguity in a very short time if accurate continuous monitoring of OLR spectrum is available (see also Schwarzkopf and Ramaswamy 2008).

The surface warming during this period (Fig. 5a) is manifested in the increase of outgoing radiances in the window regions (e.g., 833-1000, 1100-1250, 2100-2170, and beyond $2400 \mathrm{~cm}^{-1}$ ) (Fig. 4a) where the atmosphere is transparent to the surface thermal emission. The brightness temperature $\left(T_{b}\right)$ anomaly averaged from 860 to $960 \mathrm{~cm}^{-1}$ and the surface temperature $\left(T_{s}\right)$ anomaly have a correlation coefficient of 0.99 and a linear regression coefficient $\left(d T_{b} / d T_{s}\right)$ of 0.70 . When the surface temperature anomaly is large and exceeds the unforced variability (e.g., cooling in 1983 after the El Chichon eruption; warming in 1989, 1999, and beyond), the clearsky window region radiances also exceed their unforced variability. In contrast, because of the effect of clouds, the window region radiance change under all sky is less determined by the surface temperature and does not become significant until the late 1990s (Fig. 4b), although both clear-sky and all-sky radiances show a significant positive trend for the whole period (Fig. 6).

The changes in the water vapor bands (the rotational band, $100-560 \mathrm{~cm}^{-1}$, and the vibration-rotation band, $1400-2000 \mathrm{~cm}^{-1}$ ) have very fine spectral structures. 
a). clr-sky linear trend of global ocean mean radiance
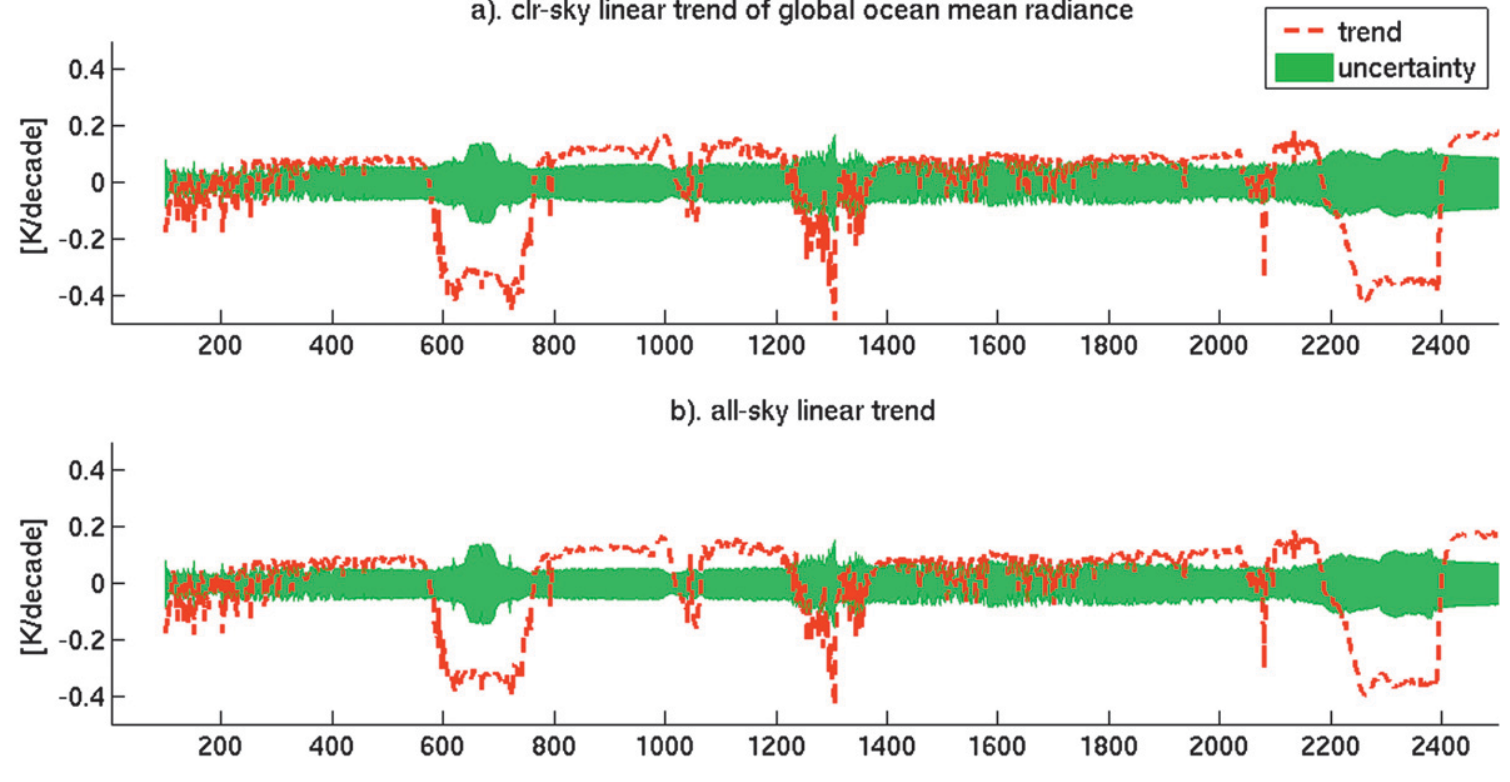

c). cloud forcing linear trend

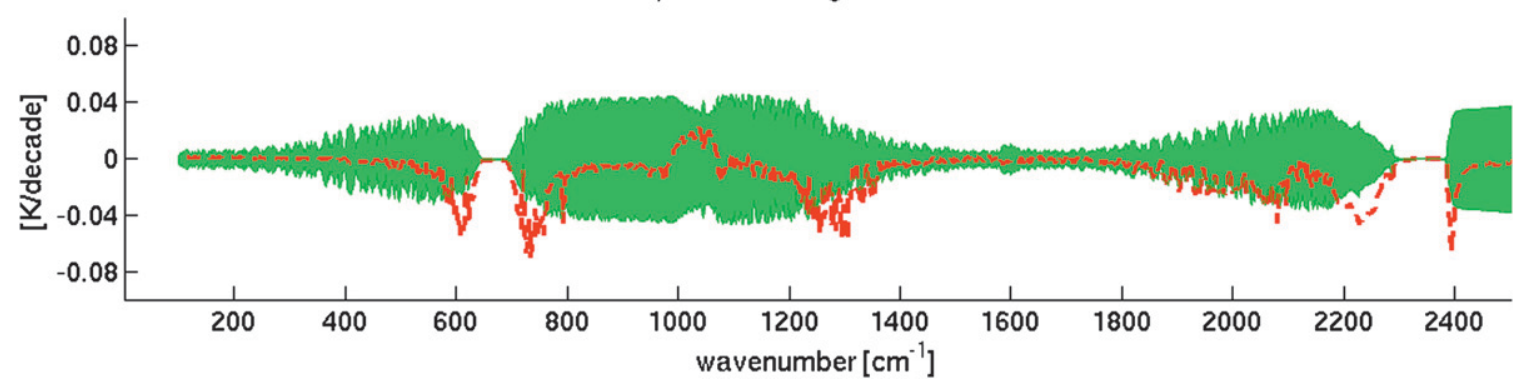

FIG. 6. Linear trend of global ocean mean (a) clear-sky radiance, (b) all-sky radiance, and (c) cloud forcing in the 25-yr period (see Fig. 4). The red dashed line is the trend estimated from linear regression; the green shaded areas envelop the uncertainty (95\% confidence level) of the trend estimation.

Radiances at these frequencies are influenced by both atmospheric temperature and water vapor concentration, which are strongly positively correlated (Figs. 5d,e; note the difference in $y$ axis scales) as a consequence of the Clapeyron-Clausius process (Held and Soden 2000) but have opposite effects on the outgoing radiation (Huang et al. 2007b). If atmospheric temperature increases, outgoing radiation increases because of a dominant Planck effect and a minor gas absorptivity effect (Huang and Ramaswamy 2007); simultaneous increase of water vapor results in more greenhouse trapping and reduces the outgoing radiation by lifting the effective emitting level (within the troposphere) to a higher and thus colder altitude. Discrete water vapor lines in these two bands are characteristic of a nearly random distribution and have a remarkable variation in their intensities (Goody and Yung 1989). In the frequency intervals (e.g., at 1506, 1540, and $1560 \mathrm{~cm}^{-1}$; see Fig. 4d) where line absorption is extremely strong and a substantial portion of the outgoing radiation emerges from the stratosphere, the radiance change may actually result from three causes: tropospheric temperature change, water vapor concentration change, and stratospheric temperature change. By using the radiative Jacobians (Huang et al. 2007b) again, a linear decomposition of the radiance change in the water vapor vibration-rotation band can be obtained (cf. Fig. 4e), which quantitatively attributes the overall change to the three possible effects. In these intervals $\left(1506,1540\right.$, and $\left.1560 \mathrm{~cm}^{-1}\right)$, the combined effect from the last two causes dominates the first one, so that the outgoing radiation decreases over this period. In the rest of the water vapor band (Fig. 4d), the stratospheric contribution is negligible. The effect of tropospheric temperature becomes dominant, and the outgoing radiation is positively correlated with temperature (cf. Figs. 4 and 5) and shows a positive trend (Fig. 6).

The change of spectral cloud forcing (defined as the clear-sky radiance minus the all-sky radiance) is most 
noticeable in the window regions (Fig. 4c). Because they are opaque, the variation of clouds may strongly affect the outgoing radiation in the window region. The correlation between the cloud forcing averaged from 860 to $960 \mathrm{~cm}^{-1}$ and the integrated total high $(<400 \mathrm{hPa})$ cloud condensate is more than $95 \%$ significant, with a coefficient of 0.70 . Meanwhile, because cloud temperature, in equilibrium with its surrounding air, is close to the atmospheric temperature at the same altitude, clouds can also enhance the effect of vertical atmospheric temperature structure change on the outgoing radiation. Suppose the clear-sky atmosphere is totally transparent and the overcast atmosphere is totally opaque; if the surface warms by $1 \mathrm{~K}$ and the atmosphere (as well as the clouds in it) warms by $2 \mathrm{~K}$, then the outgoing radiance will correspondingly increase by $1 \mathrm{~K}$ in clear sky but by $2 \mathrm{~K}$ in overcast sky. Qualitatively, this is a typical situation in simulation studies of $\mathrm{CO}_{2}$ forced climate change, owing to the moist adiabatic processes (Solomon et al. 2007). Because of this effect, the all-sky radiance trend in window regions is in fact slightly larger than the clear-sky trend (compare the difference as represented by cloud forcing in Fig. 6c). This yields a negative, although insignificant, trend of cloud forcing, despite the fact that there is no detectable decreasing trend of cloud condensate (Fig. 5f). For the same reason, there appear to be negative trends in the wings of the $\mathrm{CO}_{2}$ and $\mathrm{O}_{3}$ bands where the emitting-level-lifting effect (due to increase of greenhouse gases) is compensated by the tropospheric warming effect to a larger extent in all sky than in clear sky.

Note that the clear-sky and all-sky broadband OLR time series are stable (the changes do not exceed unforced variability except in the two years after the El Chichon and Pinatubo eruptions, respectively) and do not have a detectable trend in this 25-yr period (Fig. 5). However, spectrally resolved radiances have much more pronounced variations and exhibit a significant trend in many spectral regions (Fig. 6). The estimated trend clearly exceeds the uncertainty range in the window regions (833-1000, 1100-1200, 2100-2150, and beyond $2400 \mathrm{~cm}^{-1}$ ) where the positive radiance change is a consequence of surface warming and in the $\mathrm{CO}_{2}, \mathrm{CH}_{4}$, and $\mathrm{O}_{3}$ bands $\left(667,1310,2076\right.$ and $\left.2350 \mathrm{~cm}^{-1}\right)$ where the negative change results from increased greenhouse trapping (band wings) and stratospheric cooling (band center). In the water vapor bands (100-560 and 1400$2000 \mathrm{~cm}^{-1}$ ), the trend is negative but insignificant in the frequency intervals with strong water vapor lines; in the other frequency intervals, a positive trend barely becomes significant. The above is generally valid in both clear skies and all skies. These modeling results demonstrate that the OLR spectrum is an advantageous means for climate monitoring, being more comprehensive than merely the broadband flux. The very fine features in the water vapor bands discussed above indicate that high resolution $\left(\sim 1 \mathrm{~cm}^{-1}\right)$ is needed to resolve detailed spectral signatures of the complex and competing temperature and water vapor feedbacks, and the small magnitude of the trend signal requires an instrument stability better than $0.1 \mathrm{~K}$ decade $^{-1}$.

\section{Long-term change of OLR spectrum}

In addition to the above continuous evolution of OLR spectra, the spectra of the first and the last $5 \mathrm{yr}$ (1861-65 and 2000-04, respectively) of the CM2 integrations are also analyzed to examine the difference in spectral signatures of different forcing agents over this long period. An ensemble of three members of the Allforc experiment (cf. Schwarzkopf and Ramaswamy 2008) is used for the spectral simulation; the standard deviation between the ensemble members is used to measure the uncertainty in the desired spectrum change. The standard deviation of 5-yr means in the Nat experiment (1861-80 run) is again used as a measure of unforced variability. Note that the change here is compared to the unforced variability, which is different from the Weatherhead method used in Fig. 6.

Figure 7 illustrates the long-term global-mean OLR spectrum change from the 1861-65 mean to the 2000-04 mean forced by considering all the known forcing agents (Allforc). The difference spectra closely resemble the 25-yr trends shown in Fig. 6, with variations in the magnitude and sign from one spectral band to another. Changes in many spectral bands considerably exceed the unforced variability, in contrast to the relatively less pronounced broadband flux changes, especially in all sky (Table 1).

The most pronounced changes occur in the window regions, a manifestation of surface warming, and in the $\mathrm{CO}_{2}, \mathrm{O}_{3}$, and $\mathrm{CH}_{4}$ bands, resulting from enhanced greenhouse trapping and stratospheric cooling. These changes significantly exceed the unforced variability even after considering the ensemble variability. For instance, the largest change signal occurs in the $\mathrm{CH}_{4} 1310 \mathrm{~cm}^{-1}$ band and is about $-7 \mathrm{~K}$, which is far greater than the actual temperature change in the stratosphere illustrated later (Fig. 8).

In the water vapor bands, because of the large but compensating water vapor and temperature feedbacks, the global mean radiance change is small and is obscured by the unforced variability. However, if it is decomposed according to latitude, it can be seen that the warming signal is larger and becomes significant relative to unforced variability in the extratropics, where the tropospheric 
a). clr-sky global ocean mean radiance change

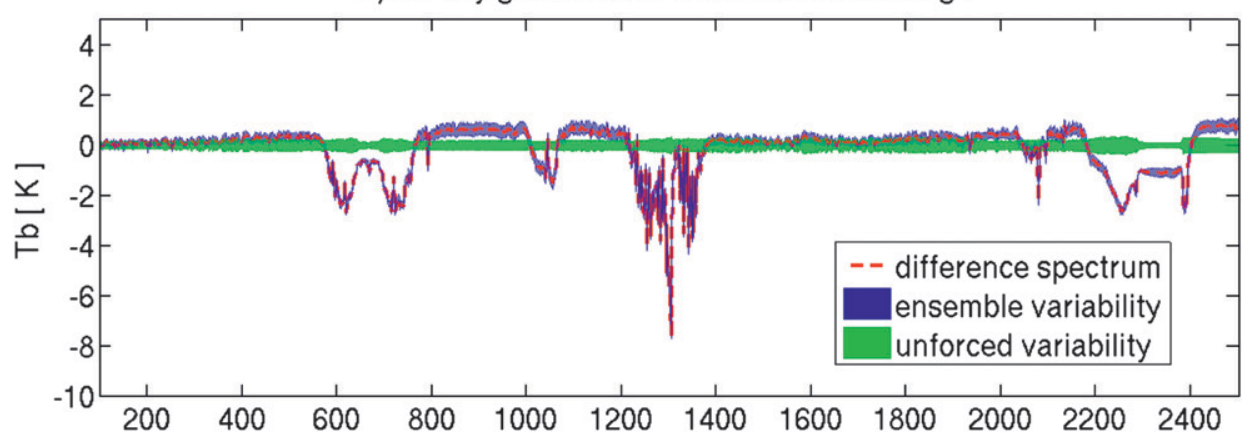

b). all-sky global ocean mean radiance change

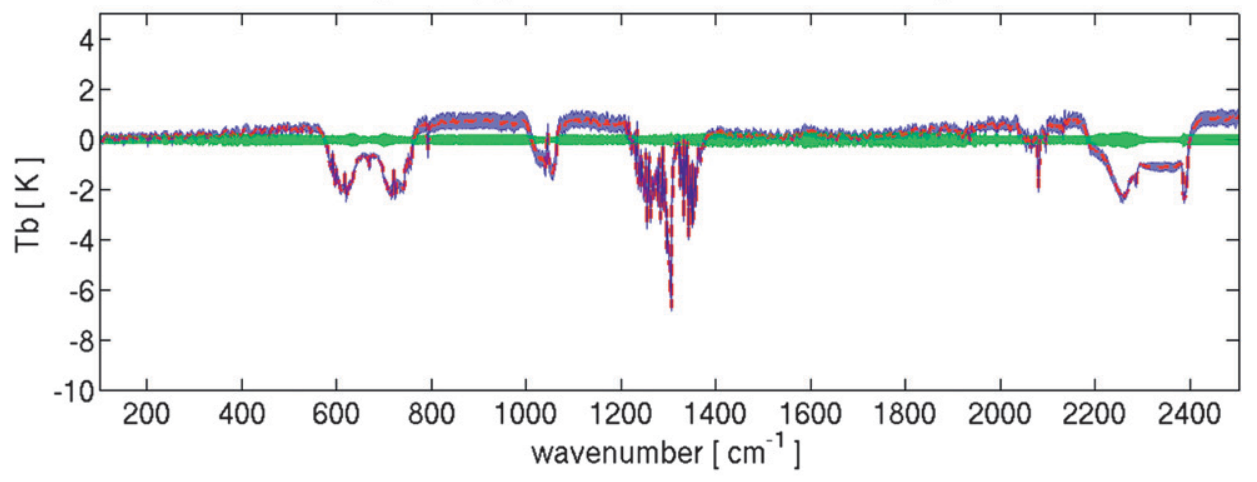

c). clr-sky low-lat ocean mean radiance change

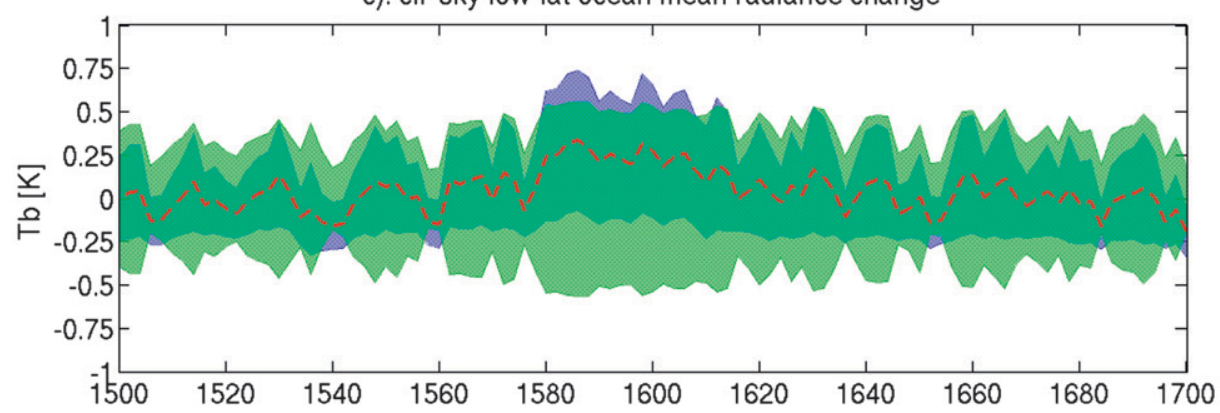

d). clr-sky mid-lat ocean mean radiance change

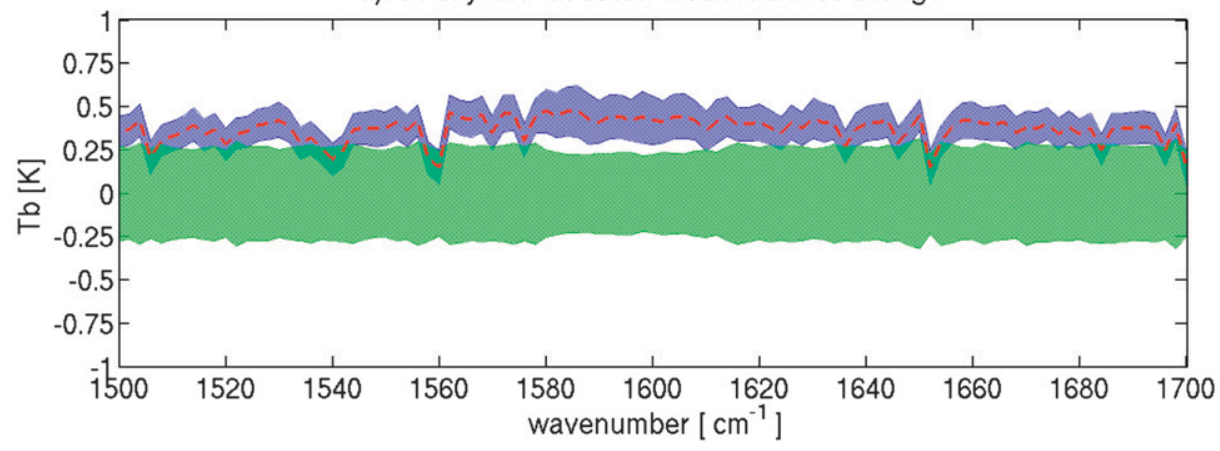

FIG. 7. (a) Clear-sky and (b) all-sky global ocean 5-yr mean spectrum change, from 1861-65 to 200004 . Also shown is the enlarged clear-sky (c) low-latitude $\left(30^{\circ} \mathrm{S}-30^{\circ} \mathrm{N}\right)$ and (d) middle-latitude $\left(30^{\circ} \mathrm{S}-\right.$ $60^{\circ} \mathrm{N}$ ) spectrum change in the water vapor band. "Ensemble variability" is 3 times the std dev of the three-ensemble-member Allforc experiment; "unforced variability" is measured by 3 times the std dev of 5-yr means in the Nat experiment. 
TABLE 1. Long-term change of global ocean 5-yr mean surface temperature $\left(T_{\mathrm{sfc}}\right)$, all-sky OLR (OLR), and clear-sky OLR $\left(\mathrm{OLR}_{c}\right)$ from 1861-65 to 2000-04 in Allforc, compared to the unforced variability given by Nat.

\begin{tabular}{|c|c|c|}
\hline & Allforc & Unforced \\
\hline & $\begin{array}{c}\langle 2000-04\rangle-\langle 1861-65\rangle \pm 3 \times \\
\text { std dev (ensemble) }\end{array}$ & $3 \times \operatorname{std}$ dev \\
\hline$T_{\text {sfc }}(\mathrm{K})$ & $0.92 \pm 0.31$ & 0.20 \\
\hline $\operatorname{OLR}\left(\mathrm{W} \mathrm{m}^{-2}\right)$ & $-0.42 \pm 0.86$ & 0.29 \\
\hline $\mathrm{OLR}_{c}\left(\mathrm{~W} \mathrm{~m}^{-2}\right)$ & $-1.50 \pm 0.66$ & 0.45 \\
\hline
\end{tabular}

warming effect is less compensated by the water vapor feedback (Figs. 7c,d).

There is no substantial difference between the clearsky and all-sky global-mean long-term spectrum changes. Although there is a noticeable increase of cloud condensate of high clouds (Fig. 8c), the window region radiance increase in all sky is slightly but insignificantly larger than that in clear sky because of the aforemen- tioned enhancement of lapse rate effect on the change in the spectral cloud forcing.

It is clear from the contrast between the $\mathrm{CO} 2$ and WmGhgO3 experiments in Fig. 9 that other greenhouse gases in addition to $\mathrm{CO}_{2}$ induce noticeable changes of OLR in the $\mathrm{CO}_{2}$ bands $\left(667 \mathrm{~cm}^{-1} ; 2300 \mathrm{~cm}^{-1}\right)$, mainly because of a stronger stratospheric cooling, and in the $\mathrm{CH}_{4}$ band $\left(1310 \mathrm{~cm}^{-1}\right)$ because of an increased $\mathrm{CH}_{4}$ trapping. However, the introduction of anthropogenic aerosols (Anth compared to WmGhgO3) and natural forcings (solar insolation and volcanic aerosols; Allforc compared to Anth) does not induce substantial changes in the OLR spectrum. This is due to the net natural forcing over the time period considered being much smaller than the anthropogenic forcing (see also Ramaswamy et al. 2001; Forster et al. 2007).

As described by Levy et al. (2008), the Allforc experiment has been extended to 2100 with the A1B radiative forcing scenario (Solomon et al. 2007). As shown in Fig. 9, under this scenario, the OLR spectral changes
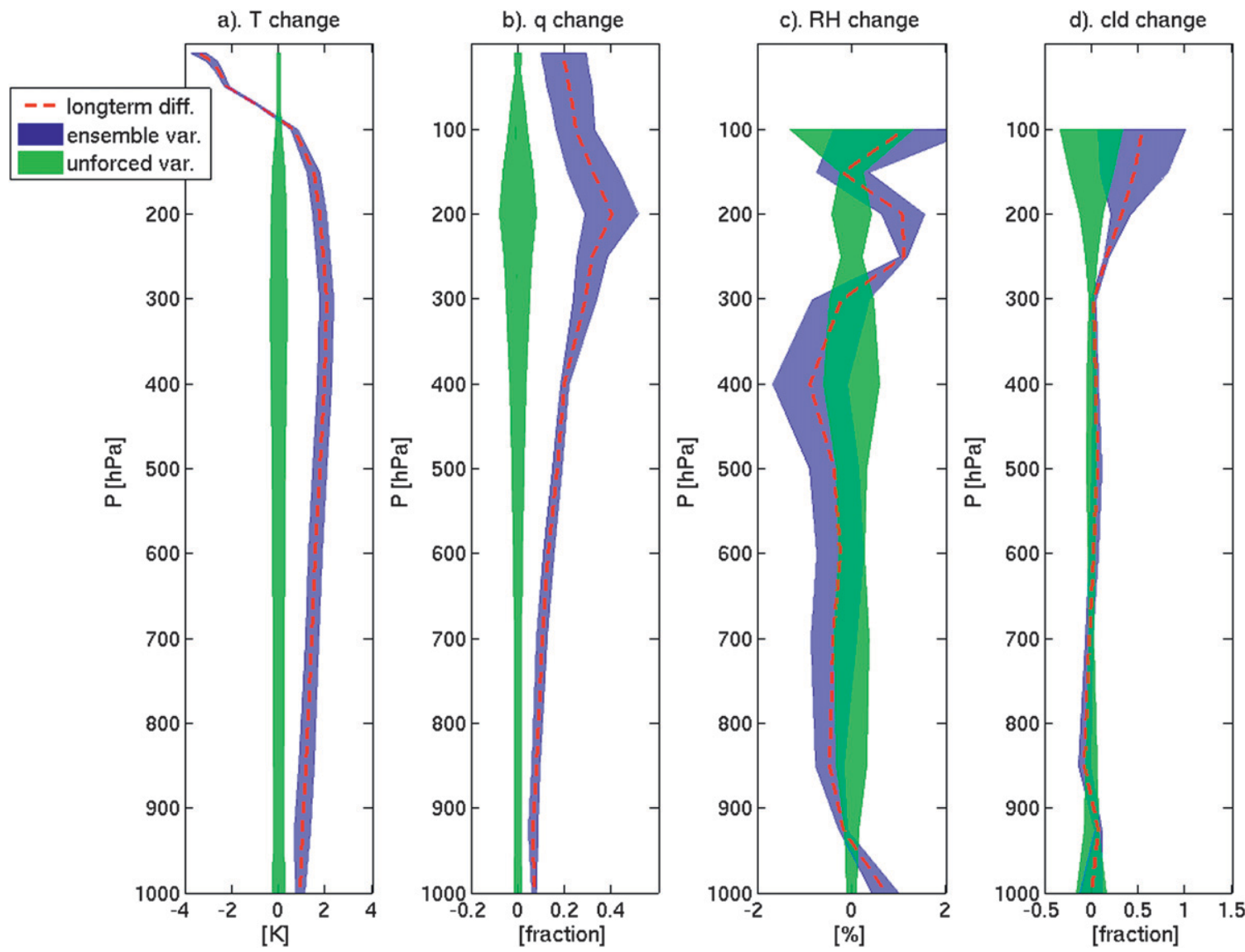

FIG. 8. Long-term change of global ocean 5-yr-mean (a) atmospheric temperature, (b) specific humidity, (c) relative humidity, and (d) cloud condensate from 1861-65 to 2000-04 in Allforc, enveloped by ensemble variability (3 times std dev) and compared to the unforced variability (3 times std dev) given by Nat. 


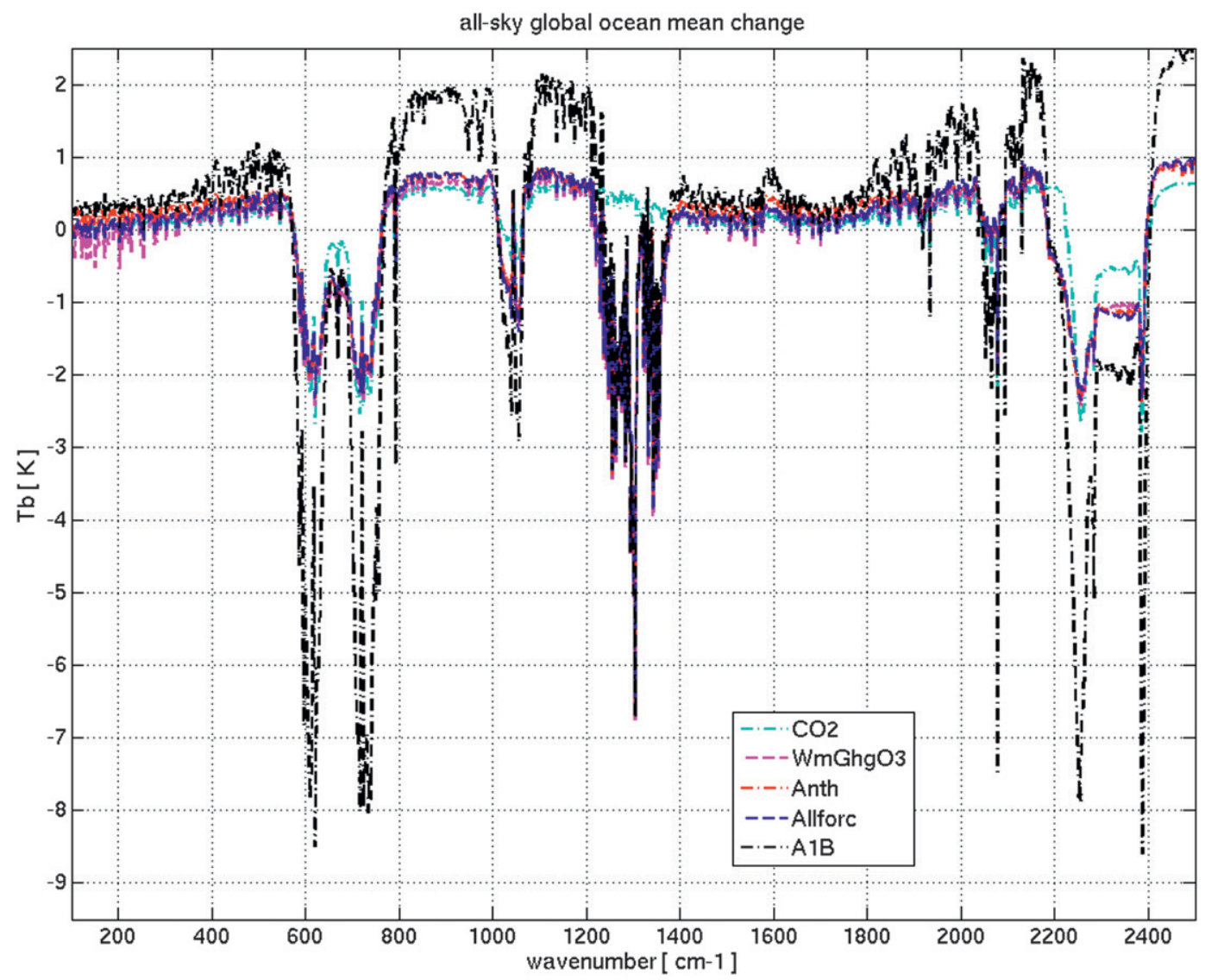

FIG. 9. Long-term difference spectra in different forcing experiments: CO2, WmGhgO3, Anth, and Allforc illustrate the spectral difference between the 2000-04 and 1861-65 means in each of these experiments (see text); A1B illustrates the difference between 2100-04 mean and 1861-65 mean in the extended Allforc integration under A1B scenario.

discussed previously are greatly amplified in the window region because of the projected surface warming and in the $\mathrm{CO}_{2}$ bands because of the projected greater cooling in the stratosphere. Because of the prescribed recovery of $\mathrm{CH}_{4}$ in the later half of the 21st century, the radiance in the $\mathrm{CH}_{4}$ band does not differ from the 2000 values. The increase of radiances in water vapor bands suggests a more substantial tropospheric warming than in 2000.

\section{Discussion}

By using a state-of-the-art GFDL GCM, we conduct an investigation into the evolution of the OLR spectrum in the context of our best knowledge of the simulated unforced and forced changes in climate. It is demonstrated that the spectrally resolved radiances in many spectral regions have much more pronounced changes than the spectrally integrated broadband fluxes under climate change. The radiance changes are controlled by the changes in temperature, water vapor, clouds, and so on happening in the troposphere and stratosphere and at the surface. Thus, monitoring the radiances provides a unique way to monitor the climate system.

In window regions where the atmosphere is largely transparent, the outgoing longwave radiance change is proportionally related to the surface temperature change; in the band center of the strong $\mathrm{CO}_{2}$ bands, the radiance mainly indicates stratospheric temperature change. In many other frequencies, although the radiances also show significant changes, they are influenced by multiple and sometimes comparable factors. For instance, in the wings of $\mathrm{CO}_{2} 667 \mathrm{~cm}^{-1}$ bands, the radiance is driven down by increased $\mathrm{CO}_{2}$ trapping and up by upper tropospheric warming. In the water vapor vibration-rotation band, water vapor concentration, upper tropospheric temperature, and lower stratospheric temperature can all influence the radiance. This makes the sign and magnitude of radiance change a delicate cancellation result that can vary abruptly with frequency and that differs from tropics to extratropics. Thus, high spectral resolution $\left(\sim 1 \mathrm{~cm}^{-1}\right)$ 
and high radiometer stability $\left(\sim 0.1 \mathrm{~K} \mathrm{decade}^{-1}\right)$ are needed to capture such spectral signatures of competing temperature and water vapor feedbacks.

The difference between clear-sky and all-sky outgoing radiation (cloud forcing) is often used as a measure of the radiative effect of clouds. As discussed by Soden et al. $(2004,2008)$ earlier, the results here caution against such a use because, for instance, the all-sky outgoing radiance in the window region, compared to the clear sky, not only relates to the total amount of radiationtrapping cloud condensate but also is influenced by the atmospheric temperature lapse rate change. Because of the latter effect, cloud forcing may change even when cloud field itself does not.

The OLR spectrum changes presented in this paper are based on the geophysical fields simulated by one particular GCM. Because of the uncertainties in the simulated geophysical fields, the simulated spectra as well as their changes could differ from reality. Indeed, model-satellite radiance discrepancies (Huang et al. 2007b; Huang and Ramaswamy 2008) reveal biases in both the mean and the seasonal variability of temperature, water vapor, and cloud fields in this model. Many aspects of the change of annual-mean OLR spectra presented in this paper can actually be used to evaluate GCM simulations. For instance, clear-sky window band and $\mathrm{CO}_{2}$ band center radiances provide valuable indices for surface and stratospheric temperature changes, respectively. The resemblance of clear-sky and all-sky window region radiance trends as simulated by the current model implies a small cloud fraction and condensate concentration change or a strong lapse rate feedback, either of which may or may not be accurate but could be validated against accurate continuous observation of the outgoing radiances. Similarly, the water vapor band radiance is influenced by multiple factors (upper tropospheric temperature, water vapor, and stratospheric temperature); by monitoring this band, the relative strengths of water vapor and temperature feedbacks can be assessed. The uncertainties in climate feedbacks are highlighted as the major cause for diverging model estimates of climate sensitivity (Bony et al. 2006); spectrally resolved radiance observations can provide a forceful metric for diagnosing this problem (Huang and Ramaswamy 2008) and for providing well-quantified solutions.

Acknowledgments. We thank Brian Soden, Isaac Held, Leo Donner, and an anonymous reviewer for their comments and good suggestions. During the course of his work, Yi Huang has been supported by a NASA Earth and Space Science Fellowship, Grant NNX06AF75H, and a NOAA Global and Climate Change Fellowship.

\section{REFERENCES}

Anderson, J., J. A. Dykema, R. M. Goody, H. Hu, and D. B. KirkDavidoff, 2004: Absolute, spectrally-resolved, thermal radiance: A benchmark for climate monitoring from space. J. Quant. Spectrosc. Radiat. Transfer, 85, 367-383.

Beer, R., 2006: TES on the Aura mission: Scientific objectives, measurements, and analysis overview. IEEE Trans. Geosci. Remote Sens., 44, 1102-1105.

Bernstein, L., A. Berk, P. Acharya, D. Robertson, G. Anderson, J. Chetwynd, and L. Kimball, 1996: Very narrow band model calculations of atmospheric fluxes and cooling rates. J. Atmos. Sci., 53, 2887-2904.

Blumstein, D., and Coauthors, 2004: IASI instrument: Technical overview and measured performances. Infrared Spaceborne Remote Sensing XII, M. Strojnik, Ed., International Society for Optical Engineering (SPIE Proceedings, Vol. 5543), 196-207.

Bony, S. R., and Coauthors, 2006: How well do we understand and evaluate climate change feedback processes? J. Climate, 19, 3445-3482.

Chahine, M., and Coauthors, 2006: AIRS: Improving weather forecasting and providing new data on greenhouse gases. Bull. Amer. Meteor. Soc., 87, 911-926.

Charlock, T., 1984: $\mathrm{CO}_{2}$-induced climatic change and spectral variations in the outgoing terrestrial infrared radiation. Tellus, 36B, 139-148.

Delworth, T. L., and Coauthors, 2006: GFDL's CM2 global coupled climate models. Part I: Formulation and simulation characteristics. J. Climate, 19, 643-674.

Forster, P., and Coauthors, 2007: Changes in atmospheric constituents and in radiative forcing. Climate Change 2007: The Scientific Basis, S. Solomon et al., Eds., Cambridge University Press, 747-845.

Goody, R., and Y. Yung, 1989: Radiation calculation in a clear atmosphere. Atmospheric Radiation: Theoretical Basis, 2nd ed., Oxford University Press, 216-287.

_ J. Climate, 11, 754-758.

_ J. Anderson, and G. North, 1998: Testing climate models: An approach. Bull. Amer. Meteor. Soc., 79, 2541-2549.

Harries, J. E., H. E. Brindley, P. J. Sagoo, and R. J. Bantges, 2001: Increases in greenhouse forcing inferred from the outgoing longwave radiation spectra of the Earth in 1970 and 1997. Nature, 410, 355-357.

Haskins, R. D., R. M. Goody, and L. Chen, 1997: A statistical method for testing a general circulation model with spectrally resolved satellite data. J. Geophys. Res., 102, 16 563-16 581.

Held, I. M., and B. Soden, 2000: Water vapor feedback and global warming. Annu. Rev. Energy Environ., 25, 441-475.

Huang, X. L., and Y. L. Yung, 2005: Spatial and spectral variability of the outgoing thermal IR spectra from AIRS: A case study of July 2003. J. Geophys. Res., 110, D12102, doi:10.1029/2004JD005530.

Huang, Y., and V. Ramaswamy, 2007: Effect of the temperature dependence of gas absorption in climate feedback. J. Geophys. Res., 112, D07101, doi:10.1029/2006JD007398.

$\longrightarrow$, and _- 2008: Observed and simulated seasonal co-variations of outgoing longwave radiation spectrum and surface temperature. Geophys. Res. Lett., 35, L17803, doi:10.1029/ 2008GL034859.

,,-- X. Huang, Q. Fu, and C. Bardeen, 2007a: A strict test in climate modeling with spectrally resolved radiances: GCM simulation versus AIRS observations. Geophys. Res. Lett., 34, L24707, doi:10.1029/2007GL031409. 
,-- , and B. Soden, 2007b: An investigation of the sensitivity of the clear-sky outgoing longwave radiation to atmospheric temperature and water vapor. J. Geophys. Res., 112, D05104, doi:10.1029/2005JD006906.

Kiehl, J., 1983: Satellite detection of effects due to increased atmospheric carbon dioxide. Science, 222, 504-506.

Knutson, T. R., and Coauthors, 2006: Assessment of twentiethcentury regional surface temperature trends using the GFDL CM2 coupled models. J. Climate, 19, 1624-1651.

Le Marshall, J., and Coauthors, 2006: Improving global analysis and forecasting with AIRS. Bull. Amer. Meteor. Soc., 87, 891-894.

Leroy, S., and Coauthors, 2008: Testing climate models using thermal infrared spectra. J. Climate, 21, 1863-1875.

Levy, H., II, M. D. Schwarzkopf, L. Horowitz, V. Ramaswamy, and K. L. Findell, 2008: Strong sensitivity of late 21st century climate to projected changes in short-lived air pollutants. J. Geophys. Res., 113, D06102, doi:10.1029/2007JD009176.

Loeb, N. G., and Coauthors, 2007: Multi-instrument comparison of top-of-atmosphere reflected solar radiation. J. Climate, 20 , 575-591.

McClatchey, R. A., R. W. Fenn, J. E. Selby, F. E. Voltz, and J. S. Garing, 1972: Optical properties of the atmosphere. AFCRL Environmental Research Paper 411, 108 pp.

National Research Council, 2007: Earth Science and Applications from Space: National Imperatives for the Next Decade and Beyond. National Academies Press, 418 pp.

Ramaswamy, V., and Coauthors, 2001: Radiative forcing of climate change. Climate Change 2001: The Scientific Basis, J. Houghton et al., Eds., Cambridge University Press, 359-416.
- M. D. Schwarzkopf, W. J. Randel, B. D. Santer, B. J. Soden, and G. L. Stenchikov, 2006: Anthropogenic and natural influences in the evolution of lower stratospheric cooling. Science, 311, 1138-1141.

Ringer, M. A., and S. B. Healy, 2008: Monitoring twenty-first century climate using GPS radio occultation bending angles. Geophys. Res. Lett., 35, L05708, doi:10.1029/2007GL032462.

Schwarzkopf, M. D., and V. Ramaswamy, 2008: Evolution of stratospheric temperature in the 20th century. Geophys. Res. Lett., 35, L03705, doi:10.1029/2007GL032489.

Slingo, A., and M. J. Webb, 1997: The spectral signature of global warming. Quart. J. Roy. Meteor. Soc., 123, 293-307.

Soden, B. J., A. J. Broccoli, and R. S. Hemler, 2004: On the use of cloud forcing to estimate cloud feedback. J. Climate, 17, 3661-3665. D. L. Jackson, V. Ramaswamy, M. D. Schwarzkopf, and X. Huang, 2005: The radiative signature of upper tropospheric moistening. Science, 310, 841-844.

, I. M. Held, R. Colman, K. M. Shell, J. T. Kiehl, and C. A. Shields, 2008: Quantifying climate feedbacks using radiative kernels. J. Climate, 21, 3504-3520.

Solomon, S., D. Qin, M. Manning, M. Marquis, K. Averyt, M. M. B. Tignor, H. L. Miller Jr., and Z. Chen, Eds., 2007: Climate Change 2007: The Physical Science Basis. Cambridge University Press, 996 pp.

Weatherhead, E. C., and Coauthors, 1998: Factors affecting the detection of trends: Statistical considerations and applications to environmental data. J. Geophys. Res., 103, 17 149-17 161.

Wittenberg, A. T., A. Rosati, N.-C. Lau, and J. J. Ploshay, 2006: GFDL's CM2 global coupled climate models. Part III: Tropical Pacific climate and ENSO. J. Climate, 19, 698-722. 